\title{
COMPUTER SIMULATION AND MODELLING SYSTEM OF NON-STATIONARY HEAT EXCHANGE PROCESSES
}

\author{
Aleksandr Pilipenko*, Sergei Petrov \\ Orel State University named after I.S.Turgenev, 302020, Oryol, Russia
}

\begin{abstract}
This article suggests the solution to the up-to-date task of improving and increasing the energy efficiency of buildings and quality of functioning of systems, controlling boilers and heating devices, by using computer simulation and modelling of heat exchange processes of the building and operation of the heating systems. The authors present proven (checked) mathematical models, applicable for external protections, rooms, heaters, boilers, insulated and non-insulated piping. The authors offer an automated system of computer simulation and modelling, which not only allows us to solve mathematical models, but also to complement them with information from a real object and improve them by introducing corrective factors and coefficients.
\end{abstract}

\section{Introduction}

The "Smart House" systems, aiming at improving energy efficiency, are being developed for more than 10 years in Europe, and new materials are being created to achieve heat and energy conservation [1]. However, it is worth considering that many of years of research on the territory with gentle climatic conditions may not be applicable in the Russian Federation, where climatic conditions differ and vary in the range from -50 to $+50{ }^{\circ} \mathrm{C}$. In this regard, the task of mathematical and computer modelling of non-stationary processes of heat exchange, which will help us to investigate the processes of mixing, convection, radiation and thermal conductivity in pipe railings and piping enclosures, protection enclosures (protective cover), walls, halls, pipelines, heating systems and boilers, is relevant and of vital importance [2]. In this paper, the authors make an attempt to describe the system of computer modelling of heat-exchange processes in various media and, under certain conditions, which will help to analyze the heating systems, rooms, buildings and other objects in details.

\section{Mathematical models}

Researches in the field of processes of conduction, convection, and radiation of heat in outdoor enclosures (possessing heat capacity or not) within the system are possible due to differential equations (1-3) and the boundary conditions (4-7):

\footnotetext{
* Corresponding author: a@pilipenko.info
} 


$$
\begin{aligned}
& \frac{\partial t_{1}(x, \tau)}{\partial \tau}=a_{1} \frac{\partial^{2} t_{1}(x, \tau)}{\partial x^{2}} \\
& \frac{\partial t_{2}(x, \tau)}{\partial \tau}=a_{2} \frac{\partial^{2} t_{2}(x, \tau)}{\partial x^{2}} \\
& \frac{\partial t_{3}(x, \tau)}{\partial \tau}=a_{3} \frac{\partial^{2} t_{3}(x, \tau)}{\partial x^{2}} \\
& \frac{\partial t_{1}}{\left.\partial x\right|_{x=0}}=-\frac{\alpha_{B}}{\lambda_{1}}\left(t_{B}-t_{C T . B}\right) \\
& \frac{\lambda_{1} \partial t 1}{\left.\lambda_{2} \partial x\right|_{x=}}=\frac{\partial t_{2}}{\left.\partial x\right|_{x=\delta_{1}}} \\
& \frac{\lambda_{2} \partial t_{2}}{\left.\lambda_{3} \partial x\right|_{x}=\delta_{2}}=\frac{\partial t_{3}}{\left.\partial x\right|_{x=}} \delta_{2} \\
& \frac{\partial t_{3}}{\left.\partial x\right|_{x=\delta_{3}}}=-\frac{\alpha_{H}}{\lambda_{3}}\left(t_{C T . H}-t_{B}\right)+\frac{q_{H}}{\lambda_{3}}
\end{aligned}
$$

where $t_{1}, t_{2}$ denote temperature of primary and secondary coolants in the heating element, ${ }^{\circ} C$; $t_{\text {CT.B }}$ denotes temperature of the inner (internal) surface of the protection enclosures (protective cover), ${ }^{\circ} \mathrm{C} ; t_{C T . H}$ denotes temperature of the outer (external) surface of the protection enclosures (protective cover), ${ }^{\circ} \mathrm{C} ; t_{\text {ok. }}$ is temperature of the inner (internal) surface of the window, ${ }^{\circ} \mathrm{C} ; \lambda_{1}, \lambda_{2}, \lambda_{3}$ denote coefficients of thermal conductivity of protection enclosures (protective cover, guard, guarding rail) layers, Watt $/ \mathrm{m}^{\circ}{ }^{\circ} \mathrm{C} ; \alpha_{\mathrm{H}}$ denotes the coefficient of heat transfer from the outer surface of the protection enclosures, Watt $/ \mathrm{m} \cdot{ }^{\circ} \mathrm{C} ; \alpha_{\mathrm{B}}$ denotes the coefficient of heat reception (heat absorption) of the inner surface of the protection enclosures, Watt $/ \mathrm{m} \cdot{ }^{\circ} \mathrm{C} ; \tau$ is time, $\mathrm{h} ; \mathrm{q}_{\mathrm{н}}$ denotes specific heat flow rates (heat flux), Watt $/ \mathrm{m}^{2} ; \delta_{1}, \delta_{2}, \delta_{3}$ denote thickness ratio of the protection enclosures (protective cover) layers, $\mathrm{m} ; \mathrm{a}_{1}, \mathrm{a}_{2}, \mathrm{a}_{3}$ denote thermal diffusivity (conductivity) coefficients of the protection enclosures (protective cover) layers, $\mathrm{m}^{2} / \mathrm{h} ; \mathrm{t}_{\mathrm{B}}$ is internal air temperature, ${ }^{\circ} \mathrm{C}$.

Investigation of the processes of heat convection and radiation in heaters (heating apparatus) and non-insulated (non-isolated) pipe-lines is usually conducted on the basis of finding the solutions of differential equations (8-10) with boundary conditions (11-12).

$$
\begin{aligned}
& c_{1} m_{1} \frac{\partial t_{1}}{\partial t}+c_{1} G l \frac{\partial t_{1}}{\partial x}=\alpha_{1} F_{1}\left(t_{C}-t_{1}\right) ; \\
& c_{c} m_{c} \frac{\partial t_{c}}{\partial \tau}=\alpha_{1} F_{1}\left(t_{1}-t_{c}\right)-\alpha_{2} F_{2}\left(t_{C}-t_{B}\right) \text {; } \\
& c_{B} m_{B}\left(t,{ }_{B}-t{ }_{B}\right)+\alpha_{2} F_{2} \int_{0}^{2}\left(t_{c} t_{S}\right) d x=\frac{\alpha Q}{d \tau} ; \\
& x=0, t_{1}(x, \tau)=t_{1}^{\prime}
\end{aligned}
$$




$$
x=l_{1} t_{1}(x, \tau)=t_{1}^{\prime}
$$

where $c_{1}, c_{2}$ denote specific heat of primary and secondary coolant (heat-transfer agent), joules $/ \mathrm{kg} \cdot{ }^{\circ} \mathrm{C} ; c_{c}$ denotes specific heat of material of the heater wall, joules $/ \mathrm{kg} \cdot{ }^{\circ} \mathrm{C} ; t$ is temperature of the coolant (heat-transfer agent) after mixing, ${ }^{\circ} \mathrm{C} ; t^{\prime}$ denotes temperature of the coolant (heat transfer agent) at the inlet of the heat exchanger (converter), ${ }^{\circ} \mathrm{C} ; \mathrm{t}^{\prime \prime}$ denotes temperature of the coolant (heat transfer agent) at the outlet of the heat exchanger (converter), ${ }^{\circ} \mathrm{C} ; c_{B}$ specific heat of air in the room, joules $/ \mathrm{m} \cdot{ }^{\circ} \mathrm{C} ; F_{1}, F_{2}$ are the heating surfaces, $\mathrm{m}^{2} ; l$ is the pipe-line length, $\mathrm{m} ; Q$ is the heat flow, Watt; $\alpha_{1}, \alpha_{2}$ denote coefficients of heat transfer from the coolant towards the pipe wall and from pipe wall towards the environment, Watt $/ \mathrm{m} \cdot{ }^{\circ} \mathrm{C} ; G$ denotes primary and secondary coolant consumption, $\mathrm{kg} / \mathrm{h} ; m_{l}$, $m_{2}$ denote weight of the primary and secondary coolant in the heating device, $\mathrm{kg} ; m_{c}, m_{6}$ denote mass of the walls and outer medium (environment), $\mathrm{kg}$; $t_{C}$ denotes temperature of the pipe-line wall, ${ }^{\circ} \mathrm{C}$.

Investigation of the processes of convection and heat conduction in isolated heat conductors becomes possible with an application of equations (13-15) with boundary conditions (16-18).

$$
\begin{gathered}
c_{1} m_{1} \frac{\partial t_{1}}{\partial t}+c_{1} G l \frac{\partial t_{1}}{\partial x}=\alpha_{1} F_{1}\left(t_{C}-t_{1}\right) ; \\
\frac{\partial t c}{\partial \tau}=a_{c} \frac{\partial^{2} t_{c}}{\partial y^{2}} 0 \leq y \leq \delta \\
\frac{\partial t}{\partial \tau}=a \frac{\partial^{2} t}{\partial y}{ }_{u}^{2} \delta<y \delta \\
\frac{\partial t_{c}}{\left.\partial y\right|_{y=0}}=\frac{\alpha_{1}}{\lambda_{c}}\left(t_{1}-t_{c}\right) ; \\
\frac{\lambda_{c}}{\lambda_{u}} \frac{\partial t_{c}}{\left.\partial y\right|_{y=\partial_{1}}}=\frac{\partial t_{u}}{\left.\partial y\right|_{y=\partial_{1}}} ; \\
\frac{\partial t_{u}}{\left.\partial y\right|_{y=\partial_{2}}}=\frac{\alpha_{2}}{\lambda_{u}}\left(t_{u}-t_{H} \tau\right) ;
\end{gathered}
$$

where $\lambda_{\mathrm{c}}, \lambda_{\mathrm{u}}-$ denote the pipe wall and thermal insulation thermal (heat) conductivity coefficients, Watt $/ \mathrm{m} \times \mathrm{C} ; a_{c}, a_{u}$ - denote thermal diffusivity (conductivity) coefficients of the material of the wall and and insulation, $\mathrm{m}^{2} / \mathrm{h} ; t_{t}$ - denotes external air temperature, $\mathrm{C}$.

Investigation of the behaviour of heated surface of boilers and the convection and radiation processes is possible thanks to formulas (19-20), if we take into consideration boundary conditions (21-22).

$$
c_{1} m_{1} \frac{\partial t_{1}}{\partial t}+c_{1} G l \frac{\partial t_{1}}{\partial x}=\alpha_{1} F_{1}\left(t_{c}-t_{1}\right) \text {; }
$$




$$
\begin{gathered}
c_{c} m_{c} \frac{\partial t_{c}}{\partial \tau}=q l-\alpha_{1} F_{1}\left(t_{1}-t_{c}\right) ; \\
x=0 ;(x, t)=t_{1}{ }^{\prime} \\
x=l ;(x, \tau)=t_{1}{ }^{\prime \prime}
\end{gathered}
$$

where $q$ - is a specific heat flow.

The analysis of such processes of heat transfer and exchange as radiation, convection and mixing, depending on changes in the volume of air in the room, is usually implemented with a help of using equation (23).

$$
\begin{gathered}
c_{B} V \frac{\partial t_{B}(\tau)}{\partial \tau}=Q_{O T}(\tau)+Q_{u}(\tau)+Q_{B}(\tau)-\alpha_{B} F_{B}\left(t_{B}-t_{C T}\right)- \\
-\alpha_{B} F_{H}\left(t_{B}-t_{C T . B}\right)-\alpha_{B} F_{O K} \times\left(t_{B}-t_{O K . B}\right)-c_{B} L\left(t_{B}-t_{H}\right)
\end{gathered}
$$

where $V-$ is the volume of air in the room, $\mathrm{m}^{3} ; L$ - denotes ventilation indoors, $\mathrm{kg} / \mathrm{h} ; \mathrm{F}_{\text {в }}$ - denotes the area of internal protections, $\mathrm{m}^{2} ; F_{H}$ - denotes the area of external protections (walls), $\mathrm{m}^{2} ; F_{o k}$ - is the area of the window, $\mathrm{m}^{2} ; Q_{O T}$ is heat flow from the heaters of the system of heating, Watt; $Q_{u}$ - denotes heat flow due to solar radiation, Watt; $Q_{b}$ - denotes production of domestic heat, Watt.

Moreover, all the designed and applied mathematical models have been successfully tested and compared with real objects on the basis of boilers in Oryol. A plan of the experiment, including 9 tests in each of ten experiments, has been developed, and the sample size has been calculated and justified.

\section{Computer modelling}

The computer modelling system, based on LabVIEW graphical programming media, has been implemented, which originally has been developed as the system for mathematical calculations and computer modelling. The advantage of using LabVIEW in the simulation and modelling process is in availability of functions (virtual appliances and gadgets), allowing to solve differential equations in the period of time, similar to real, with a help of Runge-Kutta method (the second order) [3, 4]. The system, that performs computer simulations and modelling, sensor data collection and analysis of results, as well as defining the correction coefficient and including it into a mathematical model, has been created during the work progress.

Collection of information from the sensors is the function, which can be switched off, and can be replaced by manual typing of information, performed by the user. However, the authors believe that the product will be useful for engineers, working in the field of automation, as well as builders, technologists and energy transmission and transfer engineers, who can work directly on the analyzed object and, after having been connected to the existing sensors through data collection device NI USB- $6008[5,6]$, can enter and input the actual data from the object into the computer simulation and modelling system.

The front panel of the program has been designed in the form of five paged (riffled) tabs, thus, helping us to control work in a proper way at every separate stage (level). On the first tab (Figure 1), the key parameters, such as mathematical models, wall and pipelines materials, heating systems, etc. are being selected with a help of the database. Moreover, on the first tab there is a panel of graphs, that represent the generalized solution of 
mathematical models. On the second tab there are graphs for each individual parameter. On the third tab the solution of mathematical models in the form of an array representation (Figure 2), as well as differential equations with substituted known values and corrective coefficients, are being displayed. On the fourth paged through window the graphs of values, obtained from sensors, are being displayed. The fifth tab displays the correction coefficients and the graphs, which have already undergone the procedure of correction.

After having been launched, the program tests the ports and, if the sensors and ADCS (analog digital converters) are connected, you can choose the necessary options and parameters from the data collection devices. After selecting the options and parameters you can begin viewing the results of computer modelling, and information from sensors by switching tabs at the bottom of the window.

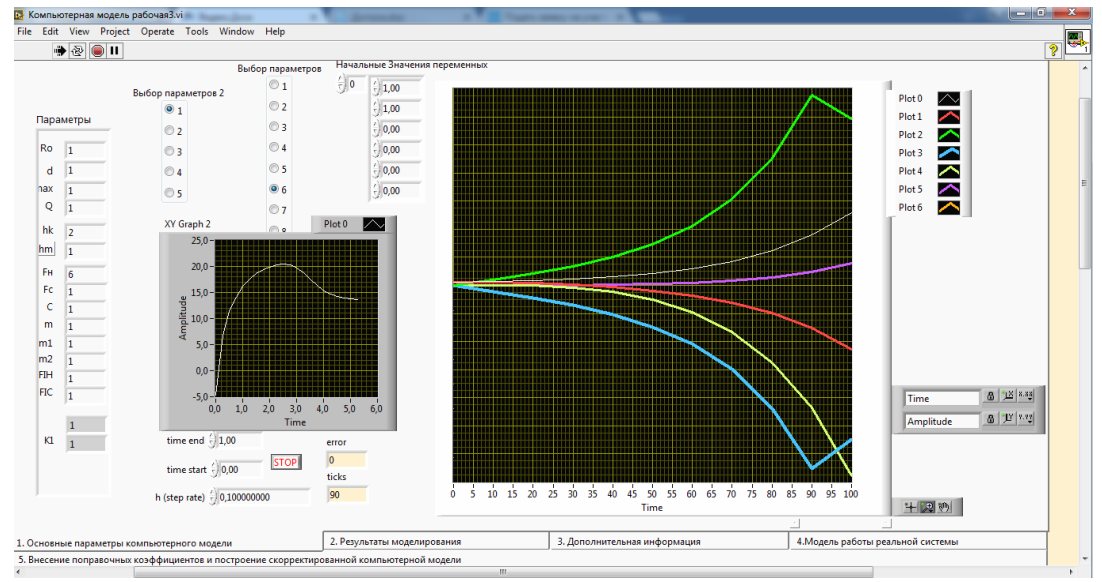

Fig. 1. The sreenshot of the main tab in computer modelling system.

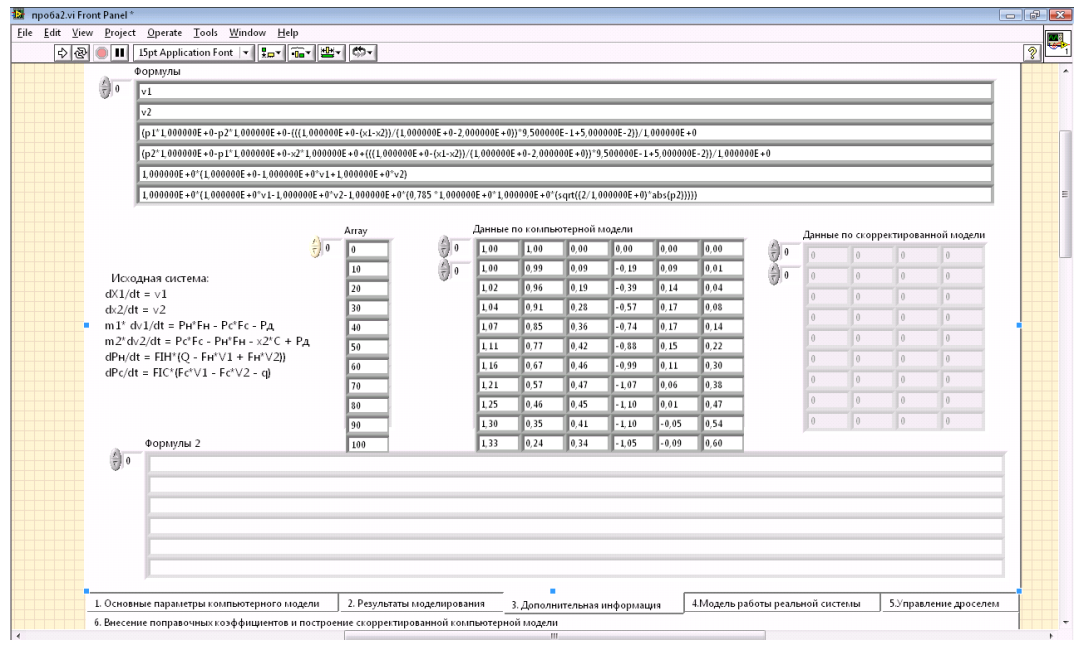

Fig. 2. The sreenshot of the tab with solution of mathematical models.

\section{Conclusion}

The use of the developed system of computer simulation and modelling allows us not only to simulate and model heat transfer processes in heating equipment and rooms, but after 
conducting measurements and imposing corrective coefficients also allows us to predict temperature fluctuations and measurements. Studies and scientific research in the field of heat exchange processes of the building is carried out before connecting any type of utilities, conveniences and facilities, as well as while conducting the processes of automation and modernization of old, obsolete rooms and buildings. The thorough and detailed analysis of heat exchange processes and selection of relevant parameters of the equipment operation allows us to increase the energy efficiency of buildings and to improve the quality of functioning of regulation and control systems. The work was carried out within the framework of the basic part of the State task for 2017 - 2019, project code 1.5265 .2017

\section{References}

[1] S.Z. Gu, J.W. Yang, J.R. Liu, China Soft Science 1, 1 (2013)

[2] S.P. Petrov Analysis and synthesis of control systems of thermal energy transfer process in the cogeneration system of central heating (Publishing House "Orlik \& K", Orel, 2009)

[3] U.G. Pirumov, Numerical methods (Drofa, Moscow, 2003)

[4] A.V. Pilipenko, Fundamental and applied problems of technique and technology 62, 58 (2012)

[5] G. B. Wiersma, Environmental Monitoring (CRC Press, New York, 2004).

[6] Liu Gaoqiang, Wu Weilin , MATEC Web of Conferences 61, (2016) doi: 10.1051/matecconf/20166106006 